\title{
Early outcomes of pandemic influenza (H1N1) 2009 surveillance in Abu Dhabi Emirate, May-August 2009
}

\author{
F. Ahmed, ${ }^{1}$ F. Al Hosani, ${ }^{2}$ A. Al Mannaie ${ }^{7}$ and O. Harrison ${ }^{3}$
}

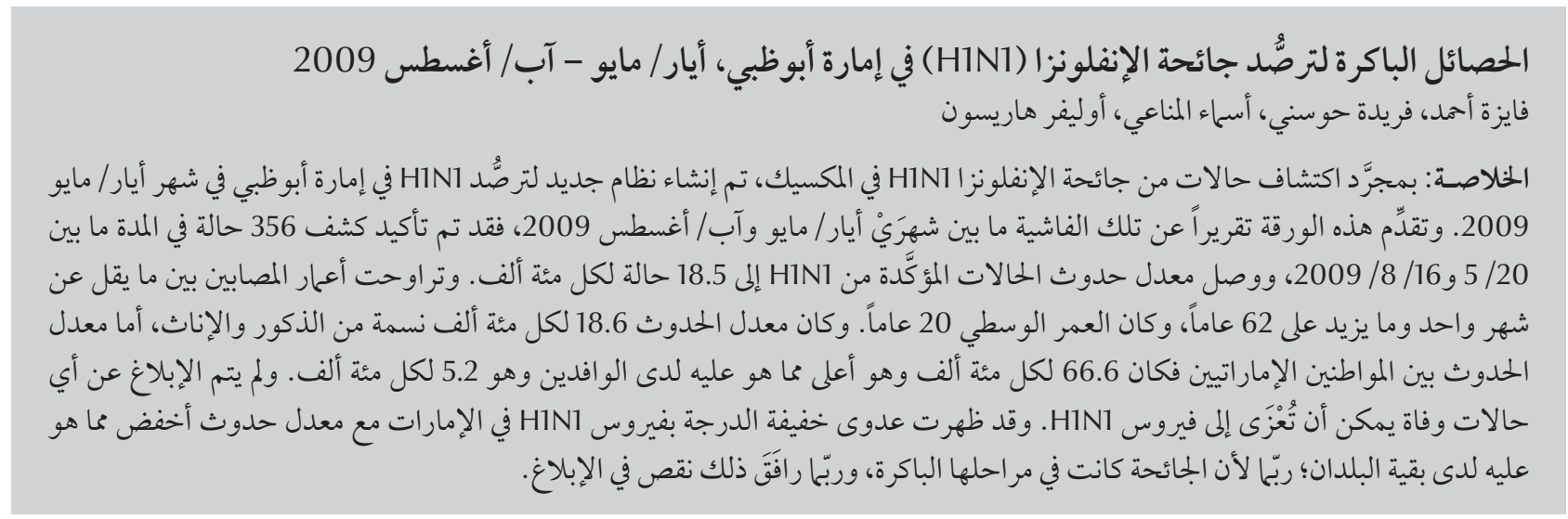

ABSTRACT Soon after the initial detection of cases of pandemic H1N1 infection in Mexico, a new H1N1 surveillance system was set up in Abu Dhabi Emirate in May 2009. This paper reports on the outbreak from May to August 2009. A total of 356 cases were confirmed from 20 May 2009 to 16 August 2009. The incidence of confirmed H1N1 cases was 18.5 per 100 000. Their ages ranged from < 1 month to 62 years, with a median age of 20 years. The incidence was 18.6 per 100000 among both males and females. The incidence among United Arab Emirates nationals was higher than expatriates (66.6 versus 5.2 per 100 000). No death attributable to H1N1 was reported. A low-grade H1N1 infection evolved in the Emirate with an incidence lower than some other countries, possibly because of the pandemic being in the early stages, perhaps coupled with under-reporting.

Premiers résultats de la surveillance de la grippe pandémique (H1N1) dans l'Émirat d'Abu Dhabi, de mai à août 2009

RÉSUMÉ Peu de temps après les premières détections de cas d'infection parlevirus delagrippe pandémique (H1N1) au Mexique, un nouveau système de surveillance du virus H1N1 a été mis en place dans l'Émirat d'Abu Dhabi en mai 2009. Cet article rend compte de la flambée de maladie ayant eu lieu de mai à août 2009. Au total, 356 cas ont été confirmés entre le 20 mai et le 16 août. L'incidence des cas confirmés d'infection par le virus H1N1 était de 18,5 pour 100 000. Les patients avaient moins d'un mois pour le plus jeune et 62 ans pour le plus âgé, et l'âge médian était de 20 ans. L'incidence était de 18,6 pour 100000 pour les deux sexes. L'incidence de l'infection chez les ressortissants des Émirats arabes unis était supérieure à celle des expatriés (66,6 contre 5,2 pour 100 000). Aucun décès n'a été imputable au virus H1N1. Dans l'Émirat, la flambée d'infection a été mineure, caractérisée par une incidence plus faible que dans d'autres pays, peut-être parce que la pandémie débutait et que les cas ont été sous-notifiés.

${ }^{7}$ Public Health Surveillance; ${ }^{2}$ Department of Communicable Diseases; ${ }^{3}$ Directorate, Public Health and Policy Division, Health Authority for Abu Dhabi (HAAD), United Arab Emirates (Correspondence to F. Ahmed:fahmed@haad.ae).

Received: 11/03/10; accepted: 26/05/10 


\section{Introduction}

The influenza $\mathrm{H} 1 \mathrm{~N} 1$ virus pandemic first originated in Mexico in March 2009 [1] and after about 1 month, 11 countries had reported 331 cases of influenza A (H1N1) infection to the World Health Organization (WHO) [2]. In early May 2009, the Communicable Diseases Section of the Public Health and Policy Division at the Health Authority Abu Dhabi (HAAD) started surveillance for suspected cases of $\mathrm{H} 1 \mathrm{~N} 1$, in accordance with the WHO guidelines [3]. As a result, on 20 May 2009 the first confirmed case of pandemic influenza (H1N1) 2009 was reported in the Abu Dhabi Emirate. In view of the global spread of $\mathrm{H} 1 \mathrm{~N} 1$, WHO declared the onset of phase 6 of the pandemic in June 2009 [4].

Reports from across the globe indicated a rapidly spreading mild illness [5-11], with a clearly higher incidence compared with that observed for seasonal influenza in previous years [11]. The Eastern Mediterranean Region reported 2802 cases of $\mathrm{H} 1 \mathrm{~N} 1$ and 8 deaths to WHO by 15 August 2009, with Saudi Arabia reporting the highest number of cases [12]. However, to date there are no published reports of the epidemiological characteristics of $\mathrm{H} 1 \mathrm{Nl}$ in the general population of the Arab states. Abu Dhabi Emirate, the capital of the United Arab Emirates (UAE), has a majority of immigrants among its population and the travel dynamics indicated by passenger growth [13] would be expected to contribute to a different risk profile for $\mathrm{H} 1 \mathrm{~N} 1$ infection.

In Abu Dhabi, pandemic H1N1 surveillance marked the beginning of influenza surveillance operations. This report is about the development of the H1N1 pandemic in Abu Dhabi Emirate and the demographic distribution of $\mathrm{H} 1 \mathrm{~N} 1$ cases during the pandemic period extending from 20 May to 16 August 2009 .

\section{Methods}

\section{Study setting}

Abu Dhabi is divided into 3 administrative regions: Abu Dhabi Island (the Middle region, with the largest population), Eastern (also known as Al Ain) and Western. The estimated 2009 population for Abu Dhabi was 1915 903, comprising 21\% UAE nationals and $79 \%$ expatriates [14]. The male to female ratio was $2: 1$.

$\mathrm{HAAD}$ is the health care regulatory body in Abu Dhabi Emirate and works in close collaboration with the Ministry of Health $(\mathrm{MOH})$ of UAE and other national stakeholders.

\section{H1N1 surveillance in Abu Dhabi}

When WHO raised the global alarm, after detection of the first few reported cases of H1N1 in USA and Mexico, HAAD initiated an $\mathrm{H} 1 \mathrm{~N} 1$ reporting system in May 2009 in alignment with the UAE national plan designed by $\mathrm{MOH}$. This included release of an $\mathrm{H} 1 \mathrm{~N} 1$ reporting and management protocol for health care facilities, training of health professionals and raising of community awareness using different media. In accordance with the regular practice of health statistics reporting to $\mathrm{MOH}$, H1N1 notifications were also updated by HAAD to $\mathrm{MOH}$ on a daily basis.

Abu Dhabi surveillance measures for pandemic influenza (H1N1) 2009 were as follows:

- Passive surveillance. All health care facilities, public and private, were alerted to report all suspected cases of $\mathrm{H} 1 \mathrm{~N} 1$ to HAAD using standardized $\mathrm{H} 1 \mathrm{~N} 1$ notification forms at the time of a clinical visit. Laboratory results for clinically notified cases were updated to HAAD on the same day by hospitals.

- Active surveillance. The HAAD operation centre responded to the $\mathrm{H} 1 \mathrm{~N} 1$ incident as a biological incident and coordinated the response accordingly through 24-hour active monitoring of all confirmed cases of H1N1 in hospitals.
- Case investigation and contact tracing. The case investigation form used by the physicians included: presenting symptoms, history of travel, history of pervious exposure to confirmed or suspected cases and history of close contacts exposed to the patient. The case investigation form was verified at HAAD and the contacts were called to check for developing symptoms and to refer them to a health care provider if needed.

- Screening at Abu Dhabi airport by thermal detectors. Anyone fulfilling the criteria for a suspected case was referred to hospital for further management.

The WHO case definition was used for notification of $\mathrm{H} 1 \mathrm{~N} 1$ cases in $\mathrm{Abu}$ Dhabi [15].

Prior to the H1N1 surveillance, there was no existing influenza surveillance system in Abu Dhabi. Three public hospitals in the Emirate serving each of the 3 regions of Abu Dhabi were designated as the receiving hospitals for suspected cases. Private and other clinical facilities referred suspected cases to the designated hospitals for investigation and treatment. The operations centre at HAAD was used for situation monitoring and handling communication with the different facilities involved. We report data collected through the different surveillance modalities.

\section{Management of suspected cases}

Detection of a suspected case mandated hospital admission and isolation, irrespective of disease severity. The notification was made to the HAAD at the time of the clinic visit. The attending health care professionals performed a confirmation test on all suspected cases that were admitted and treated with antiviral drugs.

\section{Laboratory testing}

Confirmation of the suspected cases was done by obtaining nasopharyngeal swabs then performing real-time reverse-transcriptase polymerase chain 
reaction assay to detect the influenza A H1N1 virus. The testing was done at the Sheikh Khalifa medical centre laboratory, which was designated as the reference laboratory for $\mathrm{H} 1 \mathrm{~N} 1$ testing. The results were reported to HAAD where the laboratory information for the already notified patients was updated.

\section{Incidence estimation}

For this paper, the incidence rates were defined as the total number of new laboratory confirmed pandemic influenza (H1N1) cases detected in Abu Dhabi from 20 May to 16 August 2009 per 100000 persons, calculated using the 2009 mid-year population estimates. The results were tabulated for the epidemiological weeks as used by WHO.

Institutional review board approval was not obtained for the study because all findings were based on data collected as a result of routine surveillance operations conducted by HAAD.

\section{Results}

The first laboratory-confirmed case was reported in Abu Dhabi on 20 May 2009. This was a 48-year-old male expatriate who had returned to UAE from Canada on 17 May. He presented to the hospital with symptoms of fever and sore throat 2 days after arrival. The patient was admitted and given antiviral treatment. The patient was confirmed to have H1N1 on 20 May 2009. He had a history of contact with 2 relatives who were also interviewed and advised to stay home for 7 days.

The total number of suspected cases of H1N1 notified in the Abu Dhabi Emirate was 1379 from 3 May to 16 August 2009. Out of these, 356 were confirmed as H1N1 cases. The incidence of pandemic influenza (H1N1) was 18.6 per 100000 . These estimates are based on the clinical cases presenting to a health care facility. There were no fatalities linked to $\mathrm{H} 1 \mathrm{~N} 1$ diagnosis in this period.

\section{Epidemic curve}

The first case of H1N1 was confirmed on 20 May 2009 (week 21) and after about 3 weeks, the second case was confirmed on 10 June. Subsequently a continuous rise was observed in the confirmed H1N1 cases until week 33 (Figure 1), the time of writing this report. The exact confirmation date was missing for 3 cases diagnosed in early August. The highest percentage (39.4\%) of confirmed cases of pandemic H1N1 among the suspected cases was seen in week 29, i.e. from 13 July to 19 July 2009.

\section{Demographic characteristics}

There were 109 (30.6\%) females and 246 (69.1\%) male cases of confirmed H1N1 (Table 1). Information on the sex of 1 case was missing. The sex distribution among the $\mathrm{H} 1 \mathrm{~N} 1$ cases followed the same pattern as in the underlying Abu Dhabi population. The incidence was the same for both males and females.

The age ranged from less than 1 month to 62 years for the 344 confirmed

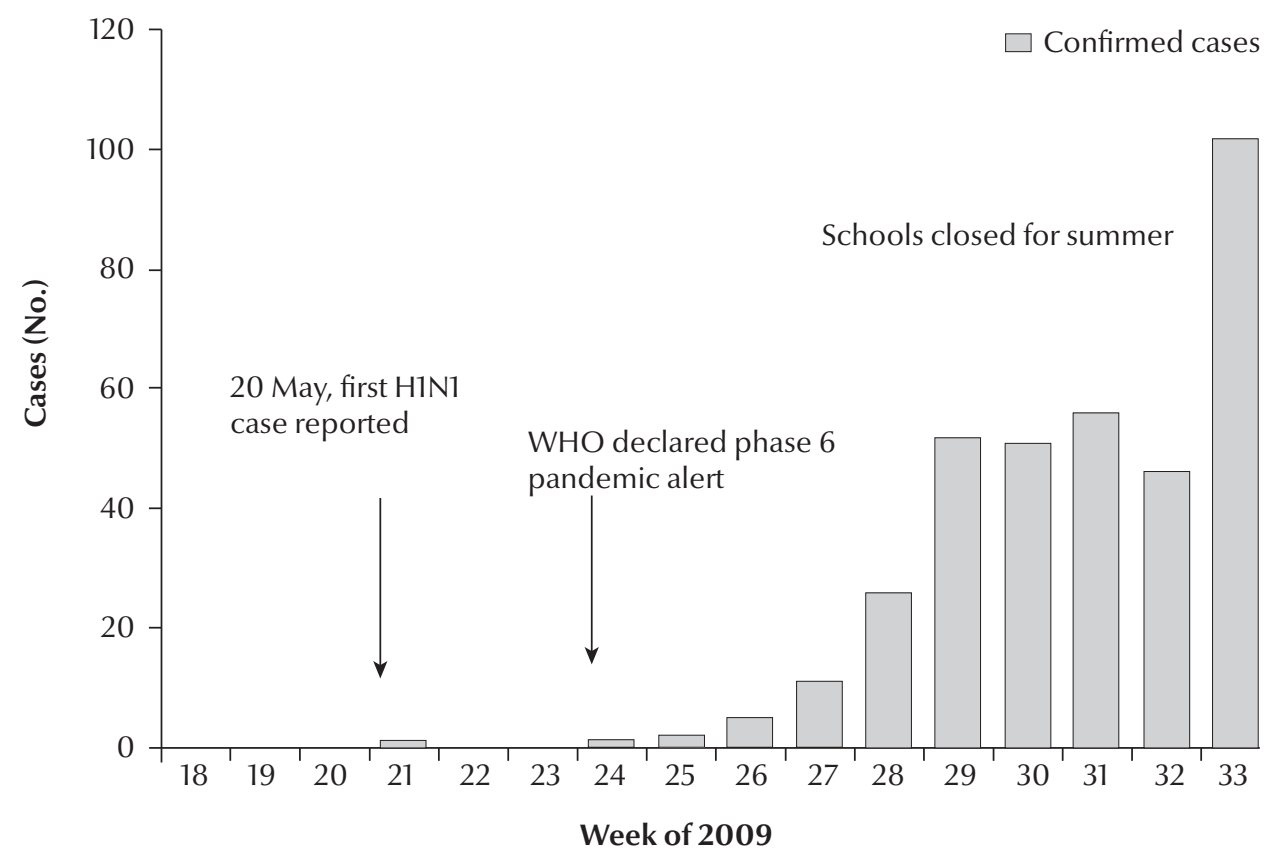

Figure 1 Pandemic influenza (H1N1) 2009 epidemic curve of confirmed cases in Abu Dhabi, 20 May to 16 August 2009 (schools were closed from week 26 to week 35 during the period that the pandemic evolved in Abu Dhabi) 


\begin{tabular}{|c|c|c|c|}
\hline Characteristic & No. of cases & $\%$ & $\begin{array}{c}\text { Incidence per } 100000 \\
\text { population }\end{array}$ \\
\hline \multicolumn{4}{|l|}{$\operatorname{Sex}^{a}$} \\
\hline Female & 109 & 30.6 & 18.5 \\
\hline Male & 246 & 69.1 & 18.5 \\
\hline \multicolumn{4}{|l|}{ Age (years) ${ }^{a}$} \\
\hline$<1$ & 6 & 1.7 & 20.6 \\
\hline $1-4$ & 36 & 10.5 & 32.6 \\
\hline $5-9$ & 37 & 10.8 & 31.6 \\
\hline $10-14$ & 32 & 9.3 & 34.2 \\
\hline 15-19 & 46 & 13.4 & 52.6 \\
\hline $20-24$ & 69 & 20.1 & 30.2 \\
\hline $25-29$ & 54 & 15.7 & 16.2 \\
\hline $30-34$ & 26 & 7.6 & 9.7 \\
\hline $35-39$ & 16 & 4.7 & 7.5 \\
\hline $40-44$ & 13 & 3.8 & 8.2 \\
\hline $45-49$ & 5 & 1.5 & 4.5 \\
\hline $50-54$ & 3 & 0.8 & 3.6 \\
\hline $55-59$ & 0 & 0.0 & 0.0 \\
\hline $60+$ & 1 & 0.3 & 2.7 \\
\hline \multicolumn{4}{|l|}{ Nationality ${ }^{a}$} \\
\hline UAE national & 271 & 76.1 & 66.6 \\
\hline Expatriate & 78 & 21.9 & 5.2 \\
\hline
\end{tabular}

${ }^{a}$ Missing data about sex for 1 case, age for 12 cases and nationality for 7 cases. $\cup A E=$ United Arab Emirates.

H1N1 cases for whom age information was available. The mean age was 20 years. Almost half $(45.6 \%)$ of the patients were aged $<20$ years. Only $1.1 \%$ of cases were aged $\geq 50$ years (Table 1 ). The highest incidence was observed in the age group of $15-19$ years (52.6 cases per 100000 people), whereas there were no $\mathrm{H} 1 \mathrm{~N} 1$ cases reported in the age group 55-59 years (Figure 2).

The incidence was notably higher among UAE nationals (66.6 per $100000)$ compared with the expatriate population (5.2 per 100000 ).

\section{Source of infection}

Information for contact and travel history was available for only 259 cases (72.8\%), out of whom about $59.1 \%$ indicated some travel in the past week, $23.9 \%$ gave no history of travel or contact with an $\mathrm{H} 1 \mathrm{~N} 1$ case and $17.0 \%$ of hospitals (94.5\%). Most of the cases (76.7\%) were notified in Abu Dhabi Island, which has $70 \%$ of the total $\mathrm{Abu}$ Dhabi population.

\section{Discussion}

To our knowledge, this populationbased surveillance report is the first of its kind in the region that describes the distribution pattern of $\mathrm{H} 1 \mathrm{~N} 1$ in one of the general populations within the Arab states. The information into the emerging pandemic influenza ( $\mathrm{H} 1 \mathrm{~N} 1)$ in $\mathrm{Abu}$ Dhabi constitutes a baseline for tracking the pandemic and also for monitoring seasonal influenza in the future.

The pandemic influenza (H1N1) 2009 period in Abu Dhabi started in the week 21 , with the index case being notified on 20 May 2009. The subsequent increase in the reported cases may have been the result of a real increase in the incidence of influenza as well as an increased reporting of the suspected cases due to increased media coverage. The peak of the epidemic in Abu Dhabi is unknown since the highest number of cases was reported in week 33, the last week covered in this report. The pandemic reached its peak relatively earlier in other parts of the world than in the Eastern Mediterranean Region [16-18]. This time lag can be attributed to the geographical transmission of H1N1 from the origin of the epidemic in the Americas to the rest of the world and also due to the lower temperatures in the southern hemisphere perhaps causing the virus to spread faster [19].

The presence of history of recent travel in about two-thirds of the cases for whom this information was available is indicative of the pandemic being in the initial stages [20], as well as the possibility of there being a low secondary attack rate. Provision of antiviral treatment of all suspected cases as a preventive strategy [20] may have further slowed the transmission rate in $\mathrm{Abu}$ Dhabi. Since schools remained closed 


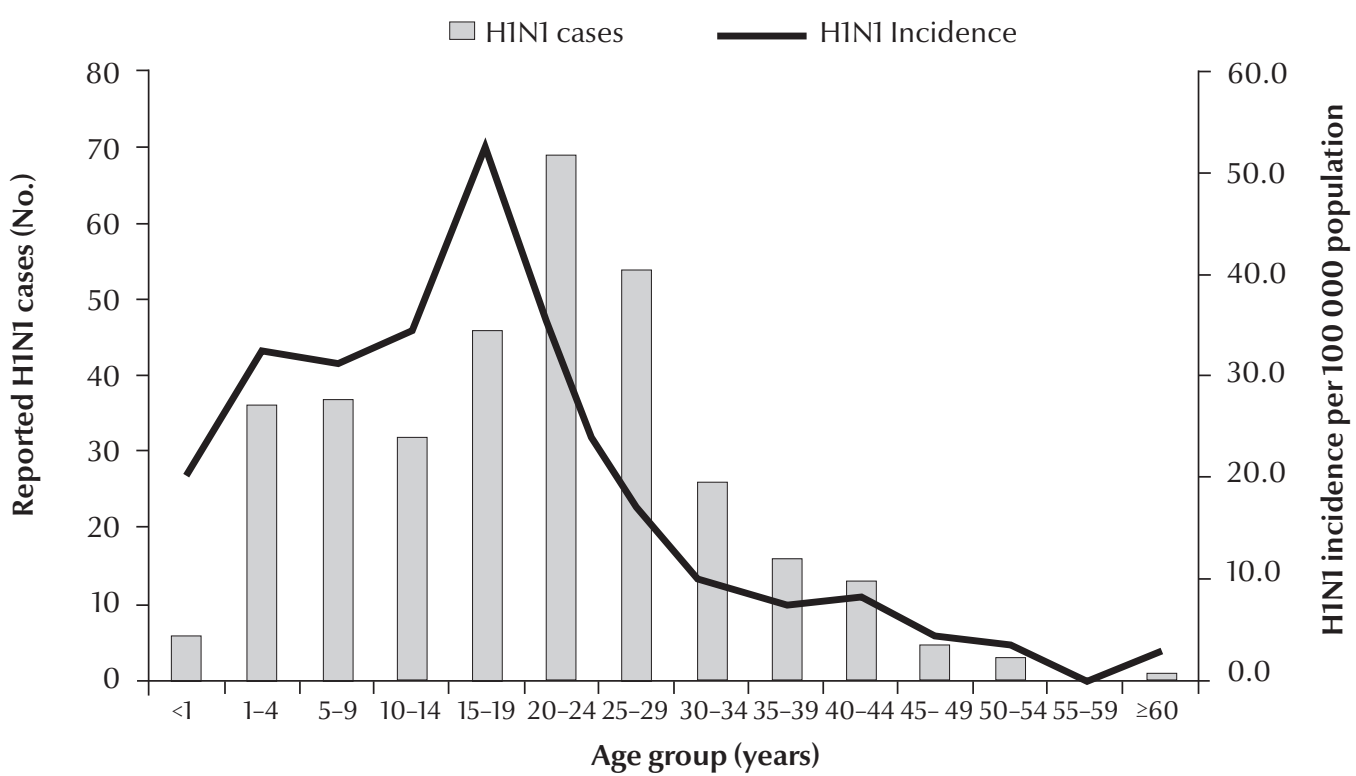

Figure 2 Pandemic influenza (H1N1) 2009 incidence by age in Abu Dhabi, 20 May to 16 August $2009(n=344)$

for the summer vacation during the early pandemic period in Abu Dhabi, the spread of infection was limited to other sources in the community.

The incidence was 18.6 per 100000 for the confirmed H1N1 cases. The incidence was lower than that in many other countries, which could be due to the pandemic being in its early stages. In addition, under-reporting of cases was another plausible reason. A population-based survey in New Zealand revealed that for every 18.3 people with influenza-like illness only 1 consulted a general practitioner [10]. Investigations in the United States have shown undercounting of influenza-like illness and pandemic $\mathrm{H} 1 \mathrm{~N} 1$ cases at various levels of patient and health care interactions [21].

As seen in different parts of the world, the infection was more common in the younger ages group (5-11 years), with the median age being 20 years. Older people may be relatively less susceptible to pandemic $\mathrm{H} 1 \mathrm{~N} 1$ because of the immunity developed from previous exposures to influenza epidemics. Males and females had a similar risk of infection. The higher proportion of males in the general population explains the greater number of male cases of H1N1. Similar demographic patterns were observed in a select group of patients in an institution-based study in Saudi Arabia [22].

Theincidence of $\mathrm{H} 1 \mathrm{~N} 1$ among $\mathrm{UAE}$ nationals was very high compared with that among expatriates ( 66.6 versus 5.2 per 100000$)$. A possible bias in case ascertainment may explain this difference. Abu Dhabi health statistics for 2008 indicated that $40 \%$ of clinical outpatient encounters were made by UAE nationals [14], although they constituted only $20 \%$ of the general population. Some of the major health facility statistics from recent years further revealed that the nationals utilized the public facilities more often (58\%) than did expatriates, who had more encounters $(81 \%)$ in private facilities [unpublished data]. A study of 5-year pneumonia hospitalizations in a university hospital in the Eastern region comprised $68 \%$ nationals [23]. The H1N1 notifications were mostly made in the public health care facilities (94.5\%) as opposed to the private facilities. Consequently, UAE nationals were a larger proportion of pandemic H1N1 cases. Although access to laboratory resources is uniform across the Emirate, differences in the notification behaviour of physicians may explain differences in the rates between the public and private sector.

The zero case fatality rate of the infection in the Abu Dhabi population during the early pandemic indicated the presence of mild disease, a similar pattern to what was generally seen worldwide. However, all cases were hospitalized and treated with antiviral therapy, which may have resulted in better disease outcomes. At the same time, we should consider the possibility that a number of undetected and unnotified cases may not have come to the attention of health care professionals, again suggesting that the severity of the infection was towards the lower end of the spectrum.

Abu Dhabi Island hosts the international airport and houses $70 \%$ of the Abu Dhabi population and the laboratory testing for $\mathrm{H} 1 \mathrm{~N} 1$ is centralized here. This explains the larger number of cases being notified from this region compared with the other 2 regions. 


\section{Conclusions}

The incidence of $\mathrm{H} 1 \mathrm{~N} 1$ was low in Abu Dhabi in the early pandemic and the possibility of under-reporting cannot be ruled out. The demographic pattern was similar to that seen in other studies. The infection had a low transmission rate, with a small proportion of locally acquired infection. Low virulence is suggested by the absence of any fatality linked to pandemic $\mathrm{H} 1 \mathrm{~N} 1$.

There is a need to investigate the reporting mechanisms in the health care sector to ensure coverage of all sectors and populations. Routine influenza surveillance can be built on the currently established H1N1 reporting system to monitor trends and identify emerging epidemics in the future.

\section{Acknowledgements}

The authors thank the health care providers who reported the suspected and confirmed cases at the health care facilities of Abu Dhabi. The authors also gratefully acknowledge Mr Krishna Narayan Pradeep in the Communicable Disease Control Section, Health Authority-Abu Dhabi, who provided valuable data management services.

\section{References}

1. Global Alert and Response (GAR). Influenza like illness in the United States and Mexico. Press release, 24 April 2009. World Health Organization (http://www.who.int/csr/ don/2009_04_24/en/index.html, accessed 31 October, 2011).

2. Global Alert and Response (GAR). Influenza A (H1N1)-update 7. Press release, 1 May 2009. World Health Organization (http://www.who.int/csr/don/2009_05_01/en/index.html, accessed 31 October, 2011).

3. Global surveillance during an influenza pandemic. Version 1. Updated draft April 2009. World Health Organization (http:// www.who.int/csr/disease/swineflu/global_pandemic_influenza_surveilance_apr09.pdf, accessed 31 October, 2011).

4. World now at the start of 2009 influenza pandemic. Press release, 11 June 2009. World Health Organization (http://www.who. int/mediacentre/news/statements/2009/h1n1_pandemic_phase6_20090611/en/index.html, accessed 31 October, 2011).

5. Novel Swine-Origin Influenza A (H1N1) Virus Investigation Team. Emergence of a novel swine-origin influenza a (H1N1) virus in humans. New England Journal of Medicine, 2009, 360:2605-2615.

6. Kelly H, Grant K. Interim analysis of pandemic influenza (H1N1) 2009 in Australia: surveillance trends, age of infection and effectiveness of seasonal vaccination. Eurosurveillance, 2009, 14(31):pii=19288.

7. Gilsdorf A, Poggensee G. on behalf of the working group pandemic influenza $\mathrm{A}(\mathrm{H} 1 \mathrm{~N} 1) \mathrm{v}$. influenza $\mathrm{A}(\mathrm{H} 1 \mathrm{~N} 1) \mathrm{v}$ in Germany: The first 10,000 cases. Eurosurveillance, 2009, 14(34):pii=19318.

8. Baker MG et al. Pandemic Influenza A (H1N1)v in New Zealand: the experience from April to August 2009. Eurosurveillance, 2009, 14(34):pii=19319.

9. Archer $\mathrm{BN}$ et al. Interim report on pandemic $\mathrm{H} 1 \mathrm{~N} 1$ influenza virus infections in South Africa, April to October 2009: epidemiology and factors associated with fatal cases. Eurosurveillance, 2009, 14(42):pii=19369.

10. Gómez J et al. Pandemic influenza in a southern hemisphere setting: the experience in Peru from May to September, 2009. Eurosurveillance, 2009, 14(42): pii=19371.

11. Turbelin C et al. Early estimates of 2009 pandemic influenza $\mathrm{A}(\mathrm{H} 1 \mathrm{~N} 1)$ virus activity in general practice in France: incidence of influenza-like illness and age distribution of reported cases. Eurosurveillance, 2009, 14(39):pii=19341.

12. New influenza A (H1N1) in Eastern Mediterranean Region: number of laboratory-confirmed cases and deaths reported to WHO, August 15, 2009. World Health Organization Regional Office for the Eastern Mediterranean [website] (http://gis.emro. who.int/MapLibrary/Files/Maps/Emro\%2016\%20August\%20 A(H1N1).jpg, accessed 31 October 2011).

13. Vine P. UAE at a glance 2009. London, Trident Press, 2009.

14. Health statistics 2008. Abu Dhabi, Health Authority Abu Dhabi, 2009.

15. Interim $W H O$ guidance for the surveillance of human infection with swine influenza A (H1N1) virus, April 27, 2009. Geneva, World Health Organization, 2009.

16. Pandemic (H1N1) 2009 virus infection in Afghanistan. WHO Weekly Epidemiological Monitor, 2009, 2(45).

17. Situation report on influenza A H1N1 pandemic-Iraq, Oct 27, 2009. World Health Organization Regional Office for the Eastern Mediterranean, 2009 [website] (http://www.emro.who. int/iraq/pdf/h1n1_27_10_09.pdf, accessed 31 October 2011).

18. Pandemic influenza A (H1N1) 2009 confirmed in Somalia. World Health Organization Regional Office for the Eastern Mediterranean [website] (http://www.emro.who.int/somalia/pdf/ WHO_Somalia_H1N1_press\%20release_09November2009. pdf, accessed 31 October 2011).

19. Global Alert and Response (GAR). Pandemic (H1N1) 2009 - update 62 (revised 21 August 2009). World Health Organization [website] (http://www.who.int/csr/don/2009_08_21/en/ index.html, accessed 31 October, 2011).

20. Nicoll A, Coulombier D. Europe's initial experience with pandemic (H1N1) 2009-mitigation and delaying policies and practices. Eurosurveillance, 2009, 14(29): pii=19279.

21. Reed C et al. Estimates of the prevalence of pandemic (H1N1) 2009, United States, April-July 2009. Emerging Infectious Diseases, 2009, 15:2004-2007.

22. Al-Khuwaitir TS et al. H1N1 influenza A. Preliminary evaluation in hospitalized patients in a secondary care facility in Saudi Arabia. Saudi Medical Journal, 2009, 30:1532-1536.

23. Al-Muhairi $S$ et al. Demographics and microbiological profile of pneumonia in United Arab Emirates. Monaldi Archives for Chest Disease, 2006, 65:13-18. 